ISSN electrónico: $1885-5210$

DOI: https://doi.org/10.14201/rmc202016113

\title{
ANIVERSARIO DE LA REVISTA MEDICINA Y CINE (2005-19). QUINCE AÑOS TIENE MI AMOR
}

\author{
Anniversary of the Journal of Medicine and Movies. Fifteen years have my love
}

Francisco S. LOZANO SÁNCHEZ

e-mail: lozano@usal.es

Departamento de Cirugía. Universidad de Salamanca (España).

Fecha de recepción: 11 de agosto de 2019

Fecha de aceptación: 2 de septiembre de 2019

Fecha de publicación: 15 de marzo de 2020

Qué se puede escribir, que no se haya escrito antes, sobre el decimo quinto aniversario de la Revista Medicina y Cine $^{1-3}$, sobre todo para alguien a quienes los editores amablemente le invitaron a festejar su aniversario, a los 5 y 10 años ${ }^{4,5}$.

En la década de sesenta, durante mi adolescencia, un reconocido y exitoso dúo musical español, denominado Dúo Dinámico popularizó una canción titulada «Quince años tiene mi amor». Espero que, a los editores de Medicina y Cine, que vieron nacer y crecer su revista, les agrade este subtítulo aparentemente frívolo.

El padre de la medicina, Hipócrates de Cos (460-370 a C) decía «Si se ama el arte de la medicina, también se ama a la humanidad». Bastantes siglos después, el padre de la moderna medicina, Wiliam Osler (1849-1919) decía
«El buen médico trata la enfermedad; el gran médico trata al paciente que tiene la enfermedad». Finalmente, el médico y académico español José de Letamendi (18281898) dijo: «El que sólo sabe medicina, ni medicina sabe». ¿Qué tienen en común estas frases? En mi opinión: que los valores de la medicina y de la profesión médica deberían ser eternos.

Los valores en general y médicos en particular, son un conjunto de cualidades positivas por los que una persona o un médico (también persona) es apreciada o considerada. La conjunción positiva de varios valores induce armonía, y ayuda a ser mejores individual y socialmente. La gran mayoría de valores (respeto, amor, libertad, justicia, tolerancia, equidad, paz, honestidad, responsabilidad, lealtad, etc.) están interrelacionados. 
Valores y virtudes son conceptos similares, pero no equivalentes; los primeros se refieren a cosas y los segundos a personas. Cuando los valores dejan de ser algo externo y teórico, para transformarse en principios internos de actuación, adquieren el nombre de virtudes.

Dicho todo esto, ¿verdaderamente existe una crisis de valores o pérdida de virtudes en la sociedad actual? Parece obvio, fundamentalmente en lo referente a pérdida de valores morales, éticos y sociales. No obstante, algunos matizan diciendo que en la sociedad actual no existe crisis de valores, sino pérdida de virtudes ${ }^{6}$.

Aunque ciertamente los valores morales son relativos (subjetivos), todos los valores los debemos relacionar con el lado positivo, bueno, útil, o valioso de las cosas. No obstante, hay valores positivos olvidados (como la disciplina), valores manipulados (como la autoridad), valores sobreestimados (como la utilidad) y valores negativos legitimados (como la picaresca). Conjuntamente la jerarquización de la escala de valores se ha manipulado, así valores como la verdad o la bondad han sido desplazados por valores económicos y utilitarios. Incluso en algunos ambientes no está bien visto de hablar de virtudes; en su lugar se habla de valores, más impersonales y menos comprometidos, o porque la virtud se suele asociar a la religión (olvidando la existencia de numerosas virtudes humanas).

En cualquiera de los casos «Cuando el río suena, agua lleva», dice un dicho español que pone el acento en que incluso los rumores pueden tener fundamento y que es preciso estar atento para ponerles solución. Analizar las múltiples causas y consecuencias de la crisis de valores y virtudes en la actual sociedad se escapa a esta editorial, pero sí podemos decir que la Revista Medicina y Cine es un medio que nos permite:

Redimirnos, a quien nos acercamos como actores activos o pasivos a la revista, pues no debemos olvidar que todos hemos contribuido, de algún modo, a la crisis de valores/virtudes.

Mantener y recuperar valores perdidos u olvidados. La revista en casi todas sus secciones/apartados fomenta los valores positivos.

Es de todos sabido que los educadores debemos ser facilitadores de valores. Educar, esencialmente debería aportar valores/virtudes. Así desde Sócrates sabemos que las virtudes no se pueden enseñar, que no se transmiten como los conocimientos; estos se adquieren en ambientes docentes y mediante las relaciones con los maestros (otra palabra que hoy no gusta) y con personas íntegras (modelos de identificación).

En esta línea de pensamiento, conocemos la existencia de estudios que demuestran el efecto positivo que la interrelación Medicina-Cine, o Medicina-Arte en su sentido más amplio, produce sobre los estudiantes de medicina ${ }^{7}$. Todo ello tiene mucho que ver con el humanismo, virtud fundamental de la práctica de la medicina.

El documental «Ser médico», presentado en el 2017, realizado con el apoyo del grupo de trabajo de bioética la Sociedad Española de Medicina Interna y el Instituto de Ética Clínica Francisco Vallés de la Universidad Europea, tenía como objetivo el promover los valores y virtudes que debe tener un médico para ser un buen médico; en última instancia se realizó con finalidad educativa, pensando fundamentalmente en los más jóvenes.

En el documental se resaltan siete virtudes fundamentales de la profesión médica. Cada virtud se asocia a un personaje destacado en la historia de la medicina española. Los elegidos fueron Santiago Ramón y Cajal (voluntad), Juan Negrín (sacrificio), Severo Ochoa (interés por la investigación), Gregorio Marañón (humanidad), Carlos Jiménez Díaz (búsqueda de la excelencia), José María Segovia de Arana (universalidad), y Luis Buzón (compromiso con los pacientes). El director de cine, José Luis Garci, que también interviene en el documental, fue demasiado contundente al afirmar que: «la medicina es la única profesión que merece la pena».

Conjuntamente un servidor es cirujano vascular. Los cirujanos debemos fomentar los valores/virtudes de los ciudadanos de a pie, de los médicos en general y de los cirujanos en particular. El conjunto de cualidades (científicas, artísticas, técnicas y humanas) del cirujano ideal, han constituido un tema poco frecuente dentro de la bibliografía médica. No es fácil caracterizarlas, tanto en el cirujano que practica cirugía convencional como en aquellos que utilizan las nuevas tecnologías. Estas últimas, no pueden significar deshumanización. Los principios éticos que han definido siempre los valores 
del cirujano son laboriosidad, dedicación a los pacientes, deseo permanente de progreso científico, serenidad, estabilidad emocional y desinterés.

Es un hecho probado que los valores/virtudes de la profesión médica y quirúrgica, mantenidos a través de la historia han contribuido a preservar la integridad de los médicos (cirujanos) y a orientar su práctica, alejada de las presiones sociales, políticas o económicas del momento imperante.

Quizás he dicho demasiadas cosas, pero parafraseando a Galileo Galilei (1564-1642): «Todas las verdades son fáciles de comprender una vez que se descubren. EI asunto es descubrirlas». La Revista Medicina y Cine y sus nuevas secciones (Arte y Medicina, Literatura y Medicina, etc.) indudablemente ayudan a descubrir estas verdades, que en ocasiones hemos olvidado.

Tres cosas, de corazón, aunque sean lugar común en este tipo de editoriales conmemorativas: 1) felicitar a los editores por su dedicación, esfuerzo y constante mejora, como lo avalan sus análisis bibliométrico ${ }^{8,9} ; 2$ ) agradecer a Medicina y Cine lo que me aporta individualmente, y 3 ) desear a la revista y sus directivos larga vida, que redundará en beneficio de todos los se acercan periódicamente a sus esplendidas páginas.

Finalmente referir que otra famosa canción del citado Dúo Dinámico lleva por titulo «Quisiera ser», pues bien, la Revista Medicina y Cine en nuestra opinión «Ya lo es».

\section{Referencias}

1. García Sánchez JE, García Sánchez E. Hacia la segunda década de la Revista Medicina y Cine. Rev Med Cine 2014;10(4):155-6.

2. García Moro M, García Sánchez JE, García Sánchez E, García Merino E. 15 años de la Revista Medicina y Cine. Rev Med Cine 2019;15(1):1-2.

3. Hidalgo A, Bordallo J, Cantabrana B. La revista Medicina y Cine, 15 años después. Una contribución al humanismo médico. Rev Med Cine 2019;15(2):63-5.

4. Lozano Sánchez FS. Revista de Medicina y Cine, 50 Aniversario. Rev Med Cine 2009;5(3):85-6.

5. Lozano Sánchez FS. Revista de Medicina y Cine, (20052014). X años, 10 claves. Rev Med Cine 2014;10(1):3-4.

6. Castillo Ceballos G. ¿Una sociedad con crisis de valores o con pérdida de virtudes?. El Confidencial Digital, 2 de abril de 2018.

7. Hidalgo A, González García, Cantabrana B. Literatura y enseñanza de la medicina. Un ejercicio docente. Rev Med Cine 2018;14(3):199-208.

8. Tarrés MC. Análisis bibiométrico de la Revista Medicina y Cine (2005-2008). Rev Med Cine 2009;5(3):106-15.

9. García Moro M, García Merino E, Tarrés MC. Análisis bibliométrico de la Revista Medicina y Cine (2009-2014). Rev Med Cine 2016;12(2):91-7.

\begin{tabular}{|l|l|} 
Francisco S. Lozano Sánchez, MD, MB, PhD, FICS, FICA, FACA, FACS. Catedrático de Cirugía \\
Vascular de la Universidad de Salamanca. Jefe de Servicio de Angiología y Cirugía Vascular \\
en el Hospital Universitario de Salamanca. Director del Departamento de Cirugía de la \\
Universidad de Salamanca. Jefe de Investigación en el Instituto de Investigación Biomé- \\
dica de Salamanca (IBSAL). Académico numerario de la Real Academia de Medicina de \\
Salamanca. Académico electo de la Real Academia Nacional de Medicina.
\end{tabular}

